\title{
The Impact of Health Promotion Activities on the Physiological, Psychological, and Social Functions of Inpatients With Chronic Mental Illness
}

\author{
Yu Li Lan ${ }^{1 *}$, Lieh Yung Ping ${ }^{2 *}$, Li Wen $\mathrm{Su}^{3}$, and Chien Chih Chen ${ }^{4}$ \\ 1'Department of Health Administration, Tzu Chi University of Science and Technology, Taiwan, R.O.C. \\ ${ }^{2}$ Department of Psychiatry, Taipei Veterans General Hospital Yuli Branch, Taiwan, R.O.C. \\ ${ }^{3}$ Department of Rehabilitation, Taipei Veterans General Hospital Yuli Branch, Taiwan, R.O.C \\ ${ }^{4}$ Department of Future Studies and LOHAS Industry, Fo Guang University, Taiwan, R.O.C.
}

\begin{abstract}
Objective To explore the impact of the participation of patients with chronic mental illness in health promotion activities on their physical, psychological, and social functions.

Methods This study included inpatient with chronic mental illness from a hospital in Eastern Taiwan. According to the experimental research design, the selected subjects were randomly divided into a health promotion group and a control group, with 60 people in each group. The health promotion team conducts health promotion activities twice a week, each for approximately 50 minutes, over the course of eight weeks (16 times in total). The measurement instrument adopts the Adult Mental Health Scale (AMHS) scale. Five experts and scholars in related fields are invited to conduct expert validity.

Results Using independent sample t-tests to analyze the changes in the two groups after 8 weeks, the physical, psychological and social problems of the health promotion group were significantly improved compared with the control group.

Conclusion Health promotion activities can alleviate the physical illness, anxiety, irritability, depression, and social distress of chronic hospitalized mental patients, and can also increase their positive and optimistic mood. It can provide chronic mental health care institutions to plan patients' physical activities or exercises.

Psychiatry Investig 2022;19(3):171-177
\end{abstract}

Keywords Mental illness; Physiology; Psychology; Social functions.

\section{INTRODUCTION}

According to the data of the Ministry of Health and Welfare of Taiwan in 2020, the number of patients with chronic mental illness in Taiwan have a certification of disability exceeds 100,000 (131,624 in total), including 1,774 extremely serious, 20,209 severe, 70,791 moderate, and 38,850 mild cases. ${ }^{1}$ Each year the number of patients has an upward trend. Patients with mental illness often have serious obstacles in re-

\footnotetext{
Received: May 26, 2021 Revised: August 26, 2021

Accepted: November 7, 2021

$\triangle$ Correspondence: Chien Chih Chen, PhD

Department of Future Studies and LOHAS Industry, Fo Guang University, No.160, Linwei Rd., Jiaosi, Yilan County 26247, Taiwan, R.O.C.

Tel: +886-3-987-1000, Fax: +886-3-987-5535, E-mail: caesar.www@gmail.com

*These authors contributed equally to this work.

(c) This is an Open Access article distributed under the terms of the Creative Commons Attribution Non-Commercial License (https://creativecommons.org/licenses/by$\mathrm{nc} / 4.0$ ) which permits unrestricted non-commercial use, distribution, and reproduction in any medium, provided the original work is properly cited.
}

gard to emotion, thinking, cognition, behavior, social function, and quality of life and have been unable to effectively manage various adaptation problems in real life over a long period of time. When mental illness becomes chronic, in addition to mental health problems, physical disability will also increase with age and can easily lead to cognitive and life dysfunction, low self-care ability, and other problems, which will reduce the quality of life. ${ }^{2,3}$

Inpatients with mental illness remain in medical institutions for a long period of time and suffer from psychological distress, pressure, and lack of individual care. Common functional disorders include those relating to psychological distress, social pressure, personal hygiene, self-management, interpersonal relations, social processing, self-care, and entertainment arrangements. ${ }^{4,5}$ Patients with mental illness are also low in motivation due to the negative symptoms of the disease, which reduces their overall activity level, and they are more likely to be obese and suffer from metabolic diseases due to taking an- 
tipsychotic drugs. ${ }^{6}$ Therefore, such patients may be overweight; this problem is more significant for them, than for an average person. ${ }^{7.8}$ Decreased metabolic rate, increased calorie intake, and decreased physical activity are likely to aggravate the risk of obesity, resulting in a significantly higher prevalence of obesity and cardiovascular disease mortality in patients with mental illness than in the general public. ${ }^{9-11}$

Appropriate physical activity can improve psychological symptoms ${ }^{12,13}$ as well as mental and physical health. ${ }^{14}$ In addition, it can increase social function and interpersonal interaction skills ${ }^{12,13}$ and have a significant impact on the quality of life of people with mental illness. ${ }^{12,15}$

Assisting patients with mental illness in improving their health maintenance and quality of life has been an issue that has been considered and valued by professionals engaged in psychiatry and rehabilitation in recent years, and increasing participation in physical fitness activities is among the important health promotion measures. In the past, relevant research on patients with chronic mental illness focused on issues such as disease symptom treatment, care management, and quality of life but rarely utilized the perspective of health promotion to encourage and maintain the health of patients.

Therefore, through physical activity-based intervention, this study allows inpatients with mental illness to engage in a sufficient level of activity to help them relax physically and mentally, reduce risk factors and side effects caused by antipsychotic drugs, improve their social functions, and delay the degradation of physical function, which, in turn, increases their quality of life and prolongs their lives.

\section{METHODS}

\section{Participants}

The participants of the study were patients with chronic mental illness living in the rehabilitation home of a hospital in Eastern Taiwan. Patients were selected for admission. Inclusion criteria: 1) stable illness, good mental condition, autonomous ability, and suitable for health promotion activities; 2) the age is over 20 years old (inclusive) and under 70 years old; 3) a person with clear consciousness and able to communicate in languages. Exclusion criteria: 1) those who are judged by psychiatrists as dementia, autism, intellectual disability, and declaring lack of capacity under guardianship (the above diagnoses are all cognitively impaired and difficult to communicate);2) the age is under 20 years old and over 70 years old.

Process of recruiting of participants: 1) two weeks before the implementation of this research plan, the researchers went to the four wards to explain the plan implementation method to chronic mental illness; 2) each ward recruited 40 people who met the sampling conditions (inclusion criteria), 160 people in four wards; 3) obtain the participant's consent; 4) randomly assign the participants to the health promotion intervention group and the control group; 5) there are a total of 40 participants who withdrew before and during the implementation of the plan, so the participation rate is $75 \%$.

This study adopted an experimental design and randomly assigned the research subjects to either a health promotion group or a control group, with 60 people in each group. The control group received regular care in the ward during the experiment and did not participate in health promotion activities. Following the experiment, health promotion activities were provided for the patients in the control group. During the experiment, the plan host evaluated the suitability of the health promotion activities. Therefore, the risks faced by participating in the intervention activities of this plan were deemed equivalent to those faced when not participating. This study was reviewed and approved by the Hualien Tzu Chi Hospital, Buddhist Tzu Chi Medical Foundation Research Ethics Committee (IRB 109-154-B).

\section{Health promotion activity design}

The intervention period of health promotion activities is $2020 / 7 / 21-9 / 11$. It is jointly performed by one occupational therapist, who is the director of the rehabilitation department, and five occupational therapists in the psychiatric ward of the hospital. It is conducted in a group manner. The training content is discussed before each activity, and each movement is standardized. In each activity, two occupational therapists lead the trainees to demonstrate and explain the exercises, and the other four occupational therapists act as facilitators, patrolling in the group and assisting the trainees to achieve their best performance. The total number of participants in each event is 66 (6 persons are instructors; 60 persons are patients in the intervention group).

The health promotion group used health promotion activities twice a week for about 50 minutes each time for a total of eight weeks (a total of sixteen times). During weeks 1 through 5 , simple initial training was adopted. From weeks 6 to 8 , advanced training was adopted to increase difficulty.

Design principles of health promotion activities: the first stage of warm-up activity (5-10 minutes) is a dynamic stretching exercise designed to raise the temperature of the whole body and improve muscle strength and joint mobility. The second stage of training activities (30 minutes) adopts the intermittent training mode of upper limb+core/lower limb+core, each with a total of 10 training movements. The duration of each group of movements was 30 seconds, with an interval of 30 seconds. A total of three rounds were performed for the upper and lower limbs of each group, and one round was performed for the core. The third stage, stretching activities (5-10 
minutes), involved static stretching. To increase the range of motion of the joints, the muscles are extended and contracted to reduce sports injuries and accelerate lactic acid metabolism.

\section{Measures}

This study uses the Adult Mental Health Scale ${ }^{16}$ developed in Taiwan as the main questionnaire. There are 28 questions in the Adult Mental Health Scale (AMHS). After exploratory factor analysis, five factors were extracted and named as "physiological concerns" (6 questions), "anxiety" (5 questions), "social distress" (6 questions), "depression" (5 questions), and "positive optimism" (6 questions). In the pre-test stage, there are 239 valid questionnaires, and the contents of 28 test questions meet the test of reliability and validity analysis; the reliability of the pre-test total scale is as high as 0.93 , and the validity of the scale is also highly correlated. The official scale surveyed the effective questionnaires in the four regions of northern, central, southern, and eastern Taiwan for 1,170 adults over the age of 20 , and established a national norm. The Cronbach a value of the total scale is 0.92 ; the half coefficient of the total scale is 0.93 ; the test-retest reliability of the total scale is 0.72 . The validity analysis of formal scales all have good convergent validity, criterion-related validity, and construct validity.

The measurement tools included the following:

1) Background information on the research object. 2) The Mental Health Questionnaire, based on the Adult Mental Health Scale (AMHS) developed by Huang et al., ${ }^{16}$ distinguishes the three perspectives of physiology, psychology, and society in regard to somatic symptom, anxiety, depression, social distress, and positive optimism. Somatic symptom belongs to the "physiology level." Depression and positive optimism belong to the "psychology level." Anxiety are belong to the "physiology level" and the "psychology level." Social distress belongs to the "society level." 3) Course activity response feedback sheet (only for the health promotion group). Five experts and scholars in related fields were invited to conduct an expert validity analysis of the questionnaire. The questionnaire was scored in three domains, importance, text clarity, and appropriateness, and the title was modified.

\section{Statistical analysis}

The researcher collected questionnaire data before and after the two groups of activities to compare the effects of health promotion activities. SPSS 22.0 (IBM Corp., Armonk, NY, USA) was used for the analysis to verify the research hypothesis. Cronbach's a was used to test the internal consistency of the items. The average value was used to show the distribution of the continuous variables. Chi-square analysis was used to explore the differences in population background variables and mental illness between the health promotion and control groups. A t test was employed to explore the differences between the two groups (i.e., the health promotion and control groups). A paired t test was used to detect differences in the health promotion group before and after intervention.

\section{RESULTS}

\section{Reliability analysis}

The Cronbach's a values of the scale in this study were all above 0.7 . According to Nunnally, ${ }^{17}$ a Cronbach's $\alpha$ value above 0.7 is considered to be a high-confidence value. There were a total of 28 questions on the questionnaire, which were divided into a pretest and a post-test. For six questions regarding physiological diseases, the pretest Cronbach's a value was 0.783 , and the post-test Cronbach's a value was 0.815 . For anxiety, the pretest Cronbach's a value was 0.788 , and the posttest Cronbach's a value was 0.779 . The pre-measurement Cronbach's $\alpha$ value of the six questions on depression was 0.850 , and the post-measurement Cronbach's a value was 0.803 . For the five social distress questions, the pretest Cronbach's $\alpha$ value was 0.864 , and the post-test Cronbach's a value was 0.886 . For positive optimism, the pretest Cronbach's a value was 0.858 , and the post-test Cronbach's a value was 0.866 (Table 1).

\section{Distribution of sample data}

A total of 120 subjects were included in this study. The results of the chi-square test showed that the inpatients in the health promotion and control groups did not reach statistically significant differences in terms of personal background variables $\left({ }^{*} \mathrm{p}<0.05\right)$. In gender, there was no statistically significant difference between the two groups $\left(\chi^{2}=0.00, \mathrm{df}=1\right.$, $\mathrm{p}>0.999)$, men and women in the health promotion group and the control group accounted for $50 \%$, respectively. Regarding age group, there was no statistically significant difference between the two groups $\left(\chi^{2}=2.74, \mathrm{df}=2, \mathrm{p}=0.254\right)$, the range of 41-60 years old accounted for the majority $(n=82,68.3 \%)$, followed by $21-40$ years old ( $n=20,16.7 \%)$. In Hospitalization year, there was no statistically significant difference between

Table 1. Reliability analysis $(\mathrm{N}=120)$

\begin{tabular}{lcccccc}
\hline \multirow{2}{*}{ Item } & \multicolumn{2}{c}{ Pretest } & & \multicolumn{2}{c}{ Post-test } \\
\cline { 2 - 3 } \cline { 6 - 7 } \cline { 5 - 6 } & $\mathrm{N}$ & Cronbach's $\alpha$ & & $\mathrm{N}$ & Cronbach's $\alpha$ \\
\hline Somatic symptom & 6 & 0.783 & & 6 & 0.815 \\
Anxiety & 5 & 0.788 & & 5 & 0.779 \\
Depression & 6 & 0.850 & & 6 & 0.803 \\
Social distress & 5 & 0.864 & & 5 & 0.886 \\
Positive optimism & 6 & 0.858 & & 6 & 0.866 \\
\hline
\end{tabular}

$\mathrm{N}$, number of questions; AMHS, Adult Mental Health Scale 
the two groups $\left(\chi^{2}=3.09, \mathrm{df}=4, \mathrm{p}=0.544\right)$, the most common number of years of hospitalization was $6-10$ years $(n=31,25.8 \%)$, followed by more than 20 years $(n=30,25 \%)$. The social function can be described as the functional performance of mental patients is comprehensively evaluated by an occupational therapist, including self-care function performance, interpersonal function performance, and job function performance, and is divided into low, moderate, or high according to their degree. In Social function, there was no statistically significant difference between the two groups $\left(\chi^{2}=1.73, \mathrm{df}=2, \mathrm{p}=0.421\right)$, the most common social function level was moderate $(n=75$, $62.5 \%)$, followed by high function ( $n=41,34.5 \%)$. Regarding the diagnosis of mental illness, there was no statistically significant difference between the two groups $\left(\chi^{2}=3.83, \mathrm{df}=5\right.$, $\mathrm{p}=0.574)$, schizophrenia was the most common $(\mathrm{n}=82,68.3 \%)$ (Table 2).

\section{Differences between health promotion group before and after health promotion intervention}

A paired-sample $t$ test was used to analyze the differences in the physical, psychological, and social functions of the health promotion group before and after participating in health promotion activities $\left({ }^{*} \mathrm{p}<0.05,{ }^{* *} \mathrm{p}<0.01,{ }^{* * *} \mathrm{p}<0.001\right)$. After eight weeks of intervention via health promotion activities, the health promotion group showed significant differences in "somatic symptom" ( $\mathrm{t}=6.73, \mathrm{df}=59, \mathrm{p}<0.001)$, "anxiety" $(\mathrm{t}=2.27, \mathrm{df}=59, \mathrm{p}=0.027)$, "depression" ( $\mathrm{t}=2.52, \mathrm{df}=$ 59, $\mathrm{p}=0.014)$, "social distress" $(\mathrm{t}=6.45, \mathrm{df}=59, \mathrm{p}<0.001)$, and "positive optimism" $(\mathrm{t}=2.98, \mathrm{df}=59, \mathrm{p}=0.004)$. "Somatic symptom" decreased from $3.47 \pm 0.65$ to $2.48 \pm 0.82$, "anxiety" decreased from $3.16 \pm 1.06$ to $2.64 \pm 1.03$, "depression" decreased from $3.19 \pm 0.93$ to $2.66 \pm 0.99$, "social distress" decreased from $3.66 \pm 0.98$ to $2.29 \pm 0.99$, and "positive optimism" increased from $3.59 \pm 0.84$ points to $3.93 \pm 0.70$ (Table 3 ).

\section{Differences of post-test measured score between the health promotion group and the control group}

According to the results of the health promotion group and the control group after 8 weeks, the health promotion group has significantly lower levels of "somatic symptom," "anxiety," "depression," and "social distress" compared to the control group. The degree of negative is significantly reduced. The

Table 2. The distribution of background variables in the two groups of patients $(N=120)$

\begin{tabular}{|c|c|c|c|c|c|}
\hline Variable & $\begin{array}{c}\text { All } \\
(\mathrm{N}=120)\end{array}$ & $\begin{array}{l}\text { Health promotion group } \\
\qquad(\mathrm{N}=60)\end{array}$ & $\begin{array}{l}\text { Control group } \\
(\mathrm{N}=60)\end{array}$ & $\chi^{2}$ & $\mathrm{p}$ value \\
\hline Gender & & & & 0.00 & $>0.999$ \\
\hline Male & $60(50)$ & $30(50)$ & $30(50)$ & & \\
\hline Female & $60(50)$ & $30(50)$ & $30(50)$ & & \\
\hline Age (years) & & & & 2.74 & 0.254 \\
\hline $21-40$ & $20(16.7)$ & $13(21.7)$ & $7(11.7)$ & & \\
\hline $41-60$ & $82(68.3)$ & $40(66.7)$ & $42(70.0)$ & & \\
\hline Over 60 & $18(15.0)$ & $7(11.7)$ & $11(18.3)$ & & \\
\hline Hospitalization (years) & & & & 3.09 & 0.544 \\
\hline Less than 5 & $20(16.7)$ & $13(21.7)$ & $7(11.7)$ & & \\
\hline $6-10$ & $31(25.8)$ & $15(25)$ & $16(26.7)$ & & \\
\hline $11-15$ & $19(15.8)$ & $10(16.7)$ & $9(15)$ & & \\
\hline $16-20$ & $20(16.7)$ & $10(16.7)$ & $10(16.7)$ & & \\
\hline More than 20 & $30(25.0)$ & $12(20)$ & $18(30)$ & & \\
\hline Social function & & & & 1.73 & 0.421 \\
\hline Low function & $4(3.3)$ & $1(1.7)$ & $3(5.0)$ & & \\
\hline Moderate function & $75(62.5)$ & $36(60)$ & $39(65.0)$ & & \\
\hline Highly functional & $41(34.2)$ & $23(38.3)$ & $18(30)$ & & \\
\hline Mental illness & & & & 3.83 & 0.574 \\
\hline Substance-related diseases & $2(1.7)$ & $1(1.7)$ & $1(1.7)$ & & \\
\hline Organic psychosis & $7(5.8)$ & $5(8.3)$ & $2(3.3)$ & & \\
\hline Schizophrenia & $96(80)$ & $47(78.3)$ & 49 (81.7) & & \\
\hline Bipolar disorder & $15(12.5)$ & $7(11.7)$ & $8(13.3)$ & & \\
\hline
\end{tabular}


Table 3. Differences between health promotion group before and after health promotion intervention $(\mathrm{N}=60)$

\begin{tabular}{lcccc}
\hline \multicolumn{1}{c}{ Item } & Pretest & Post-test & t-test & p value \\
\hline Somatic symptom & $3.47 \pm 0.65$ & $2.48 \pm 0.82$ & 6.73 & $<0.001^{* * *}$ \\
Anxiety & $3.16 \pm 1.06$ & $2.64 \pm 1.03$ & 2.27 & $0.027^{*}$ \\
Depression & $3.19 \pm 0.93$ & $2.66 \pm 0.99$ & 2.52 & $0.014^{*}$ \\
Social distress & $3.66 \pm 0.98$ & $2.29 \pm 0.99$ & 6.45 & $<0.001^{* * *}$ \\
Positive optimism & $3.59 \pm 0.84$ & $3.93 \pm 0.70$ & 2.98 & $0.004^{* *}$
\end{tabular}

${ }^{*} \mathrm{p}<0.05 ;{ }^{* *} \mathrm{p}<0.01 ;{ }^{* * *} \mathrm{p}<0.001$. SD, standard deviation; measurement tool: AMHS, Adult Mental Health Scale

Table 4. Differences of post-test measured score between the health promotion group and the control group $(\mathrm{N}=120)$

\begin{tabular}{lcccc}
\hline \multicolumn{1}{c}{ Item } & $\begin{array}{c}\text { Health } \\
\text { promotion group }\end{array}$ & $\begin{array}{c}\text { Control } \\
\text { group }\end{array}$ & t-test & p value \\
\hline $\begin{array}{l}\text { Somatic } \\
\text { symptom }\end{array}$ & $2.48 \pm 0.82$ & $3.20 \pm 0.90$ & -4.53 & $<0.001^{* * *}$ \\
Anxiety & $2.64 \pm 1.03$ & $3.11 \pm 0.70$ & -2.97 & $0.004^{* *}$ \\
$\begin{array}{l}\text { Depression } \\
\text { Social distress }\end{array}$ & $2.66 \pm 0.99$ & $3.00 \pm 0.66$ & -2.18 & $0.031^{*}$ \\
Positive & $2.29 \pm 0.99$ & $2.67 \pm 1.01$ & -2.08 & $0.040^{*}$ \\
optimism & $3.93 \pm 0.70$ & $3.78 \pm 0.76$ & 1.08 & $0.028^{*}$ \\
\hline
\end{tabular}

${ }^{*} \mathrm{p}<0.05 ;{ }^{* *} \mathrm{p}<0.01 ;{ }^{* * *} \mathrm{p}<0.001$. SD, standard deviation; measurement tool: AMHS, Adult Mental Health Scale

"positive optimism" of the health promotion group was significantly higher than that of the control group, and the degree of positive optimism was significantly.

Using independent sample t-test analysis found that the two groups showed statistically significant differences after 8 weeks $\left({ }^{*} \mathrm{p}<0.05,{ }^{* *} \mathrm{p}<0.01,{ }^{* * *} \mathrm{p}<0.001\right)$, that the two groups showed statistically significant differences in "somatic symptom" ( $\mathrm{t}=-4.53, \mathrm{df}=119, \mathrm{p}<0.001)$, "anxiety" ( $\mathrm{t}=-2.97, \mathrm{df}=119$, $\mathrm{p}=0.004)$, "depression" ( $\mathrm{t}=-2.18, \mathrm{df}=119, \mathrm{p}=0.031$ ), "social distress" ( $\mathrm{t}=-2.08, \mathrm{df}=119, \mathrm{p}=0.040)$, and "positive optimism" $(\mathrm{t}=1.08, \mathrm{df}=119, \mathrm{p}=0.028)$ (Table 4$)$.

\section{DISCUSSION}

This study found that the participation of inpatients with chronic mental illness in health promotion activities significantly improved their physical, psychological, and social functions. Appropriate physical activity intervention can help patients achieve physical and psychological health benefits simultaneously and can also prevent diseases and achieve the purpose of promoting health. Through the intervention of physical activity courses, providing correct exercise methods, attitudes, and concepts can help patients learn how to increase the amount of physical activity in their lives and develop regular exercise habits.
Patients with mental illness who have been hospitalized for a long period of time view the hospital as their home, lack sensory stimulation, and are affected by the course of the disease. Additionally, their cognitive function is degraded. They need to be provided more stimulation to encourage their interests. ${ }^{18}$ It is the responsibility of medical staff to help patients improve their quality of life as well as their sense of power. Long-term use of antipsychotic drugs in patients with mental illness can cause periodic or chronic side effects related to being overweight, and such patients may also experience drowsiness, akithasia, dizziness, and physical exhaustion. ${ }^{6,19}$ Thus, this is an important medical problem that the medical industry urgently needs to take note of and attempt to resolve. After participating in health promotion activities, the inpatients with chronic mental illnesses in this study showed significant improvement in their physiological problems, similar to Chen et al. ${ }^{20}$ After aerobic exercise intervention; in that study, it was found that in overweight psychiatric patients had the highest average physical health score before, during and after exercise. The physical health of the exercise group also improved, compared with the control group. After participating in health promotion activities, the inpatients with chronic mental illness in this study showed significant improvement in psychological aspects, such as anxiety, irritability, and depression, and their positive optimism also significantly improved. Past studies have also found that exercise training can improve both positive symptoms and depression in cases of mental illness, ${ }^{21,22}$ effectively reduce anxiety and psychological stress, including reducing participants' auditory hallucinations, increasing self-esteem, and improving sleep, ${ }^{13,23,24}$ and improve subjective well-being. ${ }^{23} \mathrm{~A}$ study by Hsu et al. ${ }^{25}$ also found that stretching exercises and aerobic exercises can lead participants experience more obvious health benefits, including increased vitality, weight loss, improved sleep quality, and increased mobility as well as increased emotional stability, increased self-confidence, increased concentration, a more regular life, increased social initiative, increased motivation to participate in things, and the establishment of health promotion concepts.

The research of Chen et al. ${ }^{20}$ and Acil et al..$^{26}$ found that aerobic exercise can improve the quality of life of inpatient mental patients in terms of the physical, psychological, and social environment. Moreover, Smith et al..$^{27}$ and Vancampfort et al. ${ }^{28}$ also confirmed that yoga and relaxation, and progressive muscle relaxation training can all reduce the stress and anxiety of mental patients, and improve physical and mental health. These previous research results are consistent with the effect of core strength training of this present study. The good effect of exercise training is verified again for the improvement of physical and mental health. It is a low-cost and high-efficiency treat- 
ment method. Through the demonstration of this research, it can arouse the importance of medical institutions to provide the benefits of exercise for chronic mental patients.

Research limitations include: 1) The subject of this research is a chronically inpatient mentally ill patient in a hospital in eastern Taiwan. The results of the study cannot be inferred to hospitalized mental patients across the country, nor can they be inferred to acute mental patients. Therefore, it is recommended that future studies can compare the severity of the exercise effects of different levels of hospitals or mental patients with different diseases. 2) The Mental Health Evaluation Scale of this study is a subjective and conscious evaluation of patients without physiological measurement data. Therefore, it is recommended that follow-up studies can add recorded physiological measurements before and after exercise intervention, such as weight, blood pressure, blood oxygen, and blood sugar for increasing the breadth of research.

The results of this study can provide a reference for chronic psychiatric hospitals, rehabilitation homes, rehabilitation institutions, and mental rehabilitation related training institutions to plan patients' physical activities or exercise courses in order to assist in clinical treatment and improve the healthrelated quality of life of patients with chronic mental illness. It also rouses the importance of medical institutions providing exercise courses for patients with chronic mental illness. It is recommended that exercise courses be included in the routine activities of patients with mental illness in the future, and group activities should be adopted to encourage patients to continue to participate, increase their perceived sports benefits, and reduce exercise barriers. ${ }^{29}$ This will help improve the performance of patient exercises.

\section{Availability of Data and Material}

All data generated or analyzed during the study are included in this published article (and its supplementary information files).

\section{Conflicts of Interest}

The authors have no potential conflicts of interest to disclose.

\section{Author Contributions}

Conceptualization: all authors. Formal analysis: Yu Li Lan, Chien Chih Chen. Investigation: Lieh Yung Ping, Li Wen Su. Methodology: all authors. Software: Yu Li Lan, Chien Chih Chen. Validation: all authors. Writingoriginal draft: Yu Li Lan, Chien Chih Chen. Writing_review \& editing: Yu Li Lan, Chien Chih Chen. Approval of final manuscript: all authors.

\section{ORCID iDs}

\section{Yu Li Lan}

Lieh Yung Ping

Li Wen Su

https://orcid.org/0000-0002-5502-3205

https://orcid.org/0000-0002-4926-474X

https://orcid.org/0000-0002-9074-0621

Chien Chih Chen https://orcid.org/0000-0001-7072-4707

\section{Funding Statement}

This paper was supported byTaipei Veterans General Hospital Yuli Branch, Taiwan, R.O.C. (Number: VHYL-109-06).

\section{Acknowledgments}

We express our gratitude for Taipei Veterans General Hospital Yuli Branch, TAIWAN (R.O.C.) for providing research funds and all participating without whom this study could not have been successfully completed.

\section{REFERENCES}

1. Ministry of Health and Welfare, Taiwan. ROC / Health and Welfare Statistics/ Welfare Services/ Statistics for the disabled population/ Chronic Psychosis (2020). Available at: https://dep.mohw.gov.tw/dos/ cp-2976-61106-113.html. Accessed March 31, 2020.

2. Shepherd M, Watt D, Fallon I, Smeeton N. The natural history of schizophrenia: a five-year follow-up study of outcome and prediction in a representative sample of schizophrenics. Psychol Med Monogr Suppl 1989;15:1-46.

3. Tandon R, Nasrallan HA, Keshavan MS. Schizophrenia, "just the facts" 5. Treatment and prevention. Past, present, and future. Schizophr Res 2010;122:1-23.

4. Goldman H. Defining and counting the chronically mentally ill. Hosp Community Psychiatr 1981;32:21-27.

5. Wing JK. Meeting the need of people with psychiatric disorder. Soc Psychiatry Psychiatr Epidemiol 1990;25:2-8.

6. Allison DB, Mentore JL, Heo M, Chandler LP, Cappelleri JC, Infante MC, et al. Antipsychotic-induced weight gain: a comprehensive research synthesis. Am J Psychiatry 1999;156:1686-1696.

7. Lan YL, Hsu HM, Liu WC, Tseng JL, Ping LY. Overweight in chronic mentally ill inpatients. Taiwan J Psychiatry 2006;20:305-315.

8. De Hert M, Schreurs V, Vancampfort D, Van Winkel R. Metabolic syndrome in people with schizophrenia: a review. World Psychiatry 2009; $8: 15-22$.

9. Tzeng WC, Yang CI, Lin YR, Lu RB. Nonpharmacological management of the 2nd generation antipsychotics-induced weight gain. J Formos med Assoc 2005;9:536-539.

10. Lee YY, Horng FF, Liu SJ, Lin KC. Effect of a dietary educational program on body weight control in obese psychiatric patients. Taipei City Med J 2007;4:470-479.

11. Allison DB, Newcomer JW, Dunn AL, Blumenthal JA, Fabricatore AN, Daumit GL, et al. Obesity among those with mental disorders: a National Institute of Mental Health meeting report. Am J Prev Med 2009; 36:341-350

12. Gorczynski P, Faulkner G. Exercise therapy for schizophrenia. Cochrane Database Syst Rev 2010;12:CD004412.

13. Holley J, Crone D, Tyson P, Lovell G. The effects of physical activity on psychological well-being for those with schizophrenia: a systematic review. Br J Clin Psychol 2011;50:84-105.

14. Chamove AS. Positive short-term effects of activity on behaviour in chronic schizophrenic patients. Br J Clin Psychol 1986;25:125-133.

15. Arija V, Villalobos F, Pedret R, Vinuesa A, Jovani D, Pascual G, et al. Physical activity, cardiovascular health, quality of life and blood pressure control in hypertensive subjects: randomized clinical trial. Health Qual Life Outcomes 2018;16:184.

16. Huang TW, Lee MY, Tseng JM. Adult Mental Health Scale (AMHS). Taipei: Psychological Press; 2011.

17. Nunnally JC. Psychometric Theory (2nd Edition). New York: McGrawHill; 1978.

18. Ojeda N, Sánchez P, Elizagárate E, Yöller AB, Ezcurra J, Ramírez I, et al. Course of cognitive symptoms in schizophrenia: a review of the literature. Actas Esp Psiquiatr 2007;35:263-270.

19. Allison DB, Fontaine KR, Heo M, Mentore JL, Cappelleri JC, Chandler LP, et al. The distribution of body mass index among individuals with and without schizophrenia. J Clin Psychiatry 1999;60:215-220.

20. Chen C, Ferng HK, Lee JF, Hwang SN, Kao SY, Kang SC, et al. The effect of aerobic exercise on the health-related quality of life among overweight inpatients with schizophrenia. Taiwanese J Psychiatr 2007;21: 254-262. 
21. Scheewe TW, Backx FJG, Takken T, Jörg F, van Strater ACP, Kroes AG, et al. Exercise therapy improves mental and physical health in schizophrenia: a randomised controlled trial. Acta Psychiatrica Scandinavica 2012;127:464-473.

22. Kim KW, Kim SH, Shin JH, Choi BY, Nam JH, Park SC, et al. Psychosocial, physical, and autonomic correlates of depression in Korean adults: results from a county-based depression screening study. Psychiatry Investig 2014;11:402-411.

23. Vancampfort D, Probst M, Sweers K, Maurissen K, Knapen J, De Hert $M$, et al. Relationships between obesity, functional exercise capacity, physical activity participation and physical self-perception in people with schizophrenia. Acta Psychiatr Scand 2011;123:423-430.

24. Stubbs B, Vancampfort D, Rosenbaum S, Firth J, Cosco T, Veronese N, et al. An examination of the anxiolytic effects of exercise for people with anxiety and stress-related disorders: a meta-analysis. Psychiatry Res 2017;249:102-108.

25. Hsu CY, Chang YC, Kuo CC, Su CY, Chen MD. The health benefits of exercise program and factors related to participation in people with schizophrenia. J Taiwan Occup Ther Assoc 2017;35:7-27.

26. Acil AA, Dogan S, Dogan O. The effects of physical exercises to mental state and quality of life in patients with schizophrenia J Psychiatr Ment Health Nurs 2008;15:808-815.

27. Smith C, Hancock H, Blake-Mortimer J, Eckert K. A randomised comparative trial of yoga and relaxation to reduce stress and anxiety. Complement Ther Med 2007;15:77-83.

28. Vancampfort D, De Hert M, Knapen J, Maurissen K, Raepsaet J, Deckx $\mathrm{S}$, et al. Effects of progressive muscle relaxation on state anxiety and subjective well-being in people with schizophrenia: a randomized controlled trial. Clin Rehab 2011;25:567-575.

29. Vancampfort D, De Hert M, Knapen J, Wampers M, Demunter H, Deckx $\mathrm{S}$, et al. State anxiety, psychological stress and positive well-being responses to yoga and aerobic exercise in people with schizophrenia: a pilot study. Disabil Rehabil 2011;33:684-689. 